\title{
The role of mutagenesis in defining genes in behaviour
}

\author{
Sofia IH Godinho and Patrick M Nolan*,1 \\ ${ }^{1}$ MRC Mammalian Genetics Unit, Harwell, Didcot, Oxfordshire OX11 ORD, UK
}

The study of human behavioural and psychiatric disorders benefits from the development of genetic models in mice and other organisms. Mouse mutants allow one to investigate the molecular basis of disease progression and to develop novel therapies. The number of potential mouse models is increasing dramatically through the implementation of mutagenesis screens for aberrant behavioural phenotypes. The alkylating agent $\mathrm{N}$-ethyl- $\mathrm{N}$-nitrosourea ENU is the mutagen of choice in these screens as it induces mutations at a very high rate. Progeny of chemically-mutagenised animals are screened either in systematic high-throughput test batteries or in specific low-throughput tests. Both approaches have been highly successful with large numbers of novel loci being identified and characterised. Many mutant lines are available for general research with phenotypes and genetic map positions on public websites. Of the mutant genes characterised, the majority have contributed to our knowledge of gene function in physiology and disease. The 'mutagenesis screening' approach continues to evolve through the design of new phenotyping strategies. The development of modifier screens in mice shows promise in the elucidation of complex phenotypes whereas the use of mutagenesis in combination with pharmacological agents targets specific neurochemical systems. Finally, the systematic screening approach has demonstrated that mutations are likely to affect more than one biological process. European Journal of Human Genetics (2006) 14, 651-659. doi:10.1038/sj.ejhg.5201545

Keywords: mutagenesis; behaviour; ENU; phenotype

\section{Introduction}

Despite modest success in elucidating the genetic and molecular basis of human behavioural and psychiatric disorders, many of the contributory factors remain undetermined or unclear. With the exception of a few rare disorders, no genes have been conclusively identified that are involved in the pathogenesis of common psychiatric disorders. ${ }^{1}$ Difficulties in identifying genetic factors in human studies can be attributed to a number of confounding factors such as genetic heterogeneity in sample populations and subjectivity in disorder evaluation. One

*Correspondence: Dr PM Nolan, MRC Mammalian Genetics Unit, Harwell, Didcot, Oxfordshire OX11 ORD, UK. Tel: + 441235841091 ;

Fax: + 441235 841200; E-mail: p.nolan@har.mrc.ac.uk

Received 2 August 2005; revised 20 October 2005; accepted 25 October 2005 approach in identifying genetic factors has been to focus on intermediate, measurable variables associated with neuropsychiatric conditions, so-called endophenotypes. ${ }^{2}$ Those associated with schizophrenia, for example, include deficits in prepulse inhibition (PPI), EEG abnormalities and impairments in working memory. Although this method promises to assist in unravelling the genetic complexities of neuropsychiatric disorders, no genetic studies have been reported to date, possibly due to the need for specialised recording apparatus and/or difficulties in collecting large enough samples for genetic studies.

The ultimate goal of human genetic studies has been to identify and characterise genes contributing to a particular pathological condition, eventually leading to the investigation of therapeutic targets. The use of animal models in research is essential to understand and test these processes and to understand how genes interact within biological 
systems and whole organisms. The contribution of the mouse as a model organism has been twofold. In the first instance, much effort has been aimed at characterising gene function in mice through the generation of targeted mutants that are believed to be candidates for human psychiatric and behavioural disorders. These mutants also provide opportunities for investigation of disease progression and testing of novel therapies. Bolivar et al. ${ }^{3}$ have provided a comprehensive list of behavioural phenotypes in targeted mutants. Secondly, the mouse is amenable to the development of phenotypic tests that can approximate behavioural and psychiatric traits in humans (eg. human endophenotypes such as PPI can be assessed readily in the mouse). The use of chemical mutagenesis to screen for aberrant behavioural phenotypes has increased dramatically over the past decade and has provided many novel insights into biological function. This review will illustrate the potential contribution of mutagenesis to defining genes in behavioural systems with the aim of developing new models for human disorders. Although the focus will be on screens using the alkylating agent $N$-ethyl- $N$ nitrosourea (ENU), we will also refer to mouse models that have arisen either spontaneously or through the use of targeted approaches.

\section{ENU Mutagenesis in the mouse}

The field of mouse behavioural genetics has progressed rapidly in the past decade through analysis of behavioural phenotypes in mutants produced spontaneously, through gene targeting (reverse genetics) or through screening chemically-mutagenised animals (forward genetics). In the latter category, several programmes have been initiated in concerted efforts to study phenodeviants using largescale mutagenesis screens. Many of these programmes use ENU, one of the most efficient chemical mutagens in mice. ENU induces point mutations in DNA at a rate that is far greater than other chemical mutagens. ${ }^{4}$ Theoretically, functional mutations in any gene could be identified by screening $\sim 1000$ animals. As ENU is a point mutagen, multiple allelic variants at each gene locus can potentially be identified leading to complete loss of gene function (null allele), partial loss of function (hypomorphic), gain of function (hypermorphic), dominant negative function (antimorphic) or novel gain-of-function (neomorphic). This highlights one of the major advantages of using ENU, it induces mutations leading to phenotypes that may be undetected when gene targeting is used (eg, knockouts and/or transgenics). Moreover, mutant phenotypes associated with point mutations should be more appropriate as models of human inherited disorders as these are predominantly associated with single base pair changes. Interestingly, recent applications, beyond the scope of this review, allow one to screen ENU DNA banks for mutations in specific genes, or even in gene sequences that correspond to specific functional domains in proteins. ${ }^{5}$ In addition, mutagenesis screens in other vertebrate species continue to provide alternate sources of mutant phenotypes. $^{6}$

ENU mutagenesis studies are relatively simple to set up. Males are injected intraperitoneally with ENU. Mutagenised males are crossed to wild-type females to produce offspring carrying potential dominant mutations. Recessive pedigrees can be produced by crossing founder males to second-generation daughter females. Mice are then carefully screened for phenotypes using observational, neurological, behavioural and pathological assessments. More details of mutagenesis and examples of screening protocols can be seen elsewhere. ${ }^{7,8}$ Outliers are identified qualitatively or by using statistical methods and, once inheritance and penetrance of a specific phenotype is confirmed, positional cloning and candidate gene sequence analysis is carried out (Figure 1). The success of screening programmes relies on the design of specific, reliable and discriminative phenotype assays where relevance to human disease can be established. Moreover, the successful identification of a mutation from an initial aberrant phenotype can be difficult and time-consuming. Contributory factors include reduced penetrance and expressivity of phenotypes in backcrosses, difficulties in the separation of mutant and wild-type phenotypes quantitatively, a scarcity of informative polymorphic markers in candidate regions and the possibility that a causative mutation may lie within non-coding sequence. In the following sections, we discuss some of the approaches that are currently being used and document some relevant mutant lines.

\section{High throughput screening}

Batteries of high-throughput screening protocols have been used in ENU programmes in an attempt to identify mutants in large populations of mutagenised animals. The tests, including general observational screens and automated tests (eg PPI, open field assessment) have been chosen as they approximate behaviours (endophenotypes) associated with human disorders. Examples of behavioural screens that have been implemented in mutagenesis programmes are shown in Table 1 . Several centres worldwide are screening for behavioural phenotypes and the numbers of diverse behavioural mutants are on the increase (Table 2). Centres in the UK, Canada, USA and Japan have detailed descriptions of current screening methods as well potential new behavioural mutant models available to the scientific community. A typical selection of mutants can be seen at www.neuromice.org, a website listing mutants available from phenotyping centres in the US. High throughput behavioural screens have identified a 


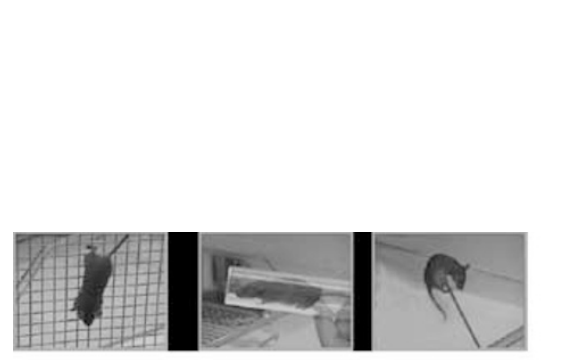

SHIRPA

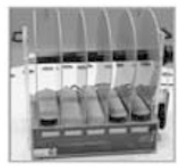

Rotarod

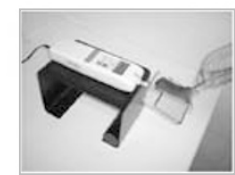

Grip strength

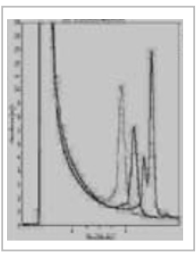

DHPLC trace

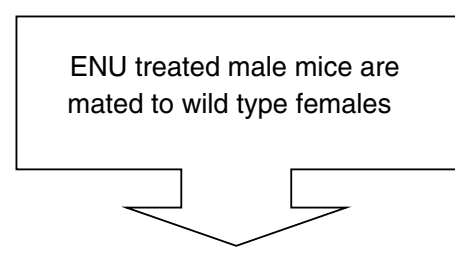

Progeny are tested for phenotypic abnormalities
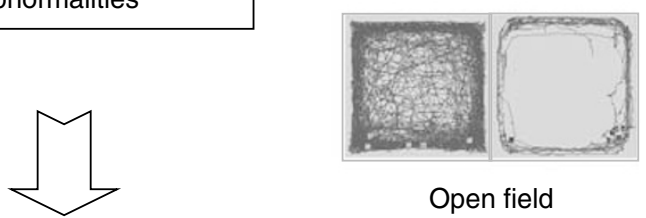

Open field

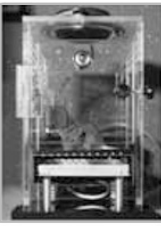

PPI
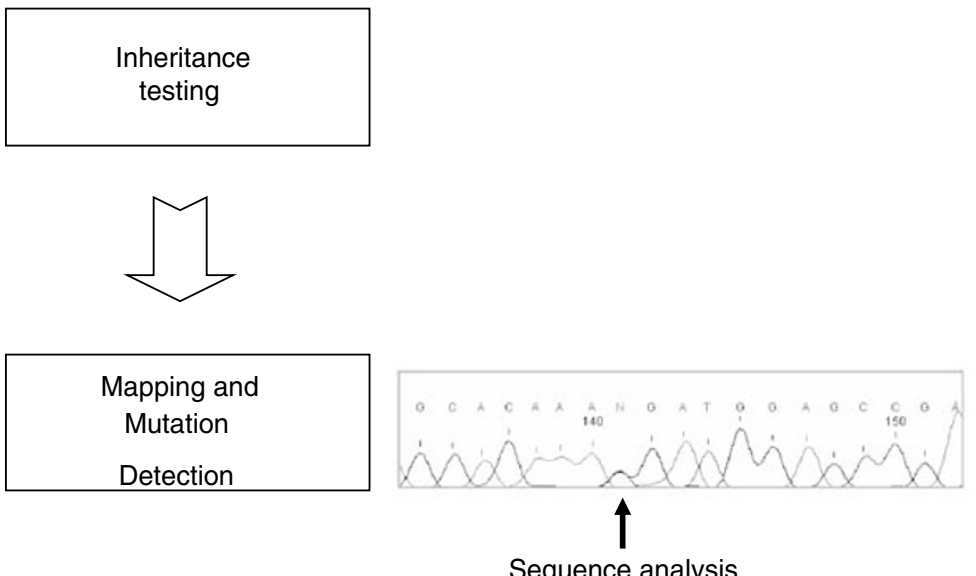

Figure 1 Screening for behavioural mutants. Flowchart illustrating the individual steps in screens for neurobehavioural mutants. Male mice are injected with ENU and mated to wild type females. Progeny are subjected to a battery of behavioural screening protocols and the phenotype of interest is confirmed through inheritance testing. Mutation detection follows through the generation of standard genetic backcross, positional cloning and candidate gene analysis.

diverse series of behavioural mutant mouse models. The mutant line 22TNJ (TMGC program) was selected in a recessive screen and maps to the distal region of chromosome 15. Homozygous mice display hyperactivity in the open field test and in response to ethanol administration. The 40TNP mouse (TMGC program) displays increased tail suspension immobility in the tail suspension test. In the mutagenesis programme at Harwell, we are currently screening for behavioural abnormalities in an effort to identify mutants using a panel of high and low-throughput phenotyping screens including observational assessment, SHIRPA analysis ${ }^{9}$ (see www.mgu.har.mrc.ac.uk/facilities/ mutagenesis/mutabase), behavioural testing and clinical chemistry. $^{8}$ In a hierarchical screen to test for anxiety phenotypes, we tested approximately 600 mice in an open field arena, with approximately 40 high- or low-anxiety mice selected for further assessment using the elevated plus maze and the dark-light box. ${ }^{10}$ Six of these mice had confirmed phenotypes and one appears to have a heritable low-anxiety phenotype. Using observational assessment, we have also identified behaviour related mutant phenotypes from our ENU screen including the robotic (Rob) mutant mouse that displays an ataxic phenotype. A mutation was found in the Af4 gene, ${ }^{11}$ previously associated with lymphoblastic leukaemias in humans and with $\mathrm{B}$ and $\mathrm{T}$ cell development in the mouse knockout. ${ }^{12} \mathrm{ENU}$ mutagenesis has thus revealed a novel CNS-related function for this gene.

High-throughput screening has provided researchers with many mouse mutants, although not in all behaviour- 
Table 1 High-throughput and low-throughput behavioural phenotyping tests used in mutagenesis screens

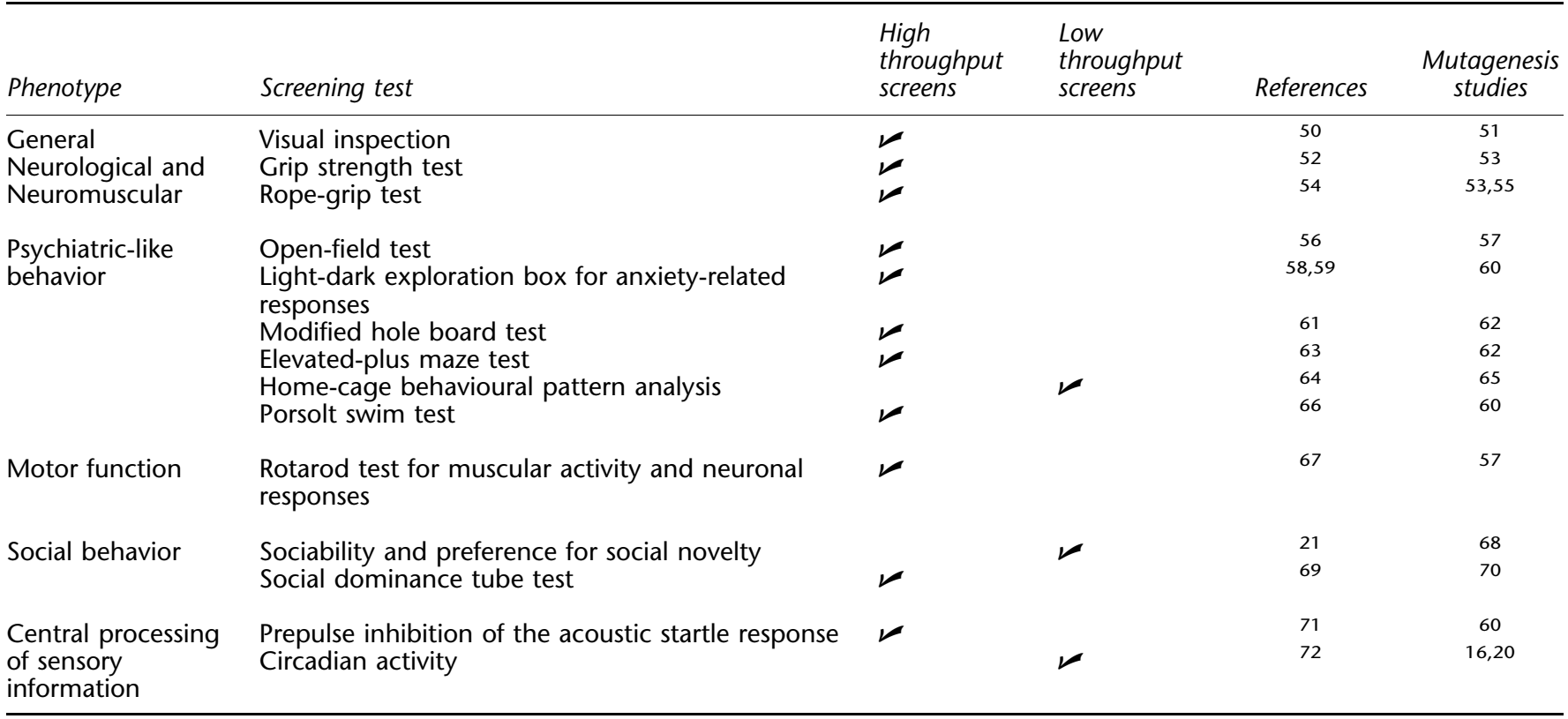

Table 2 Worldwide centres with ENU programs for behavioural mutant screens

\begin{tabular}{|c|c|c|c|}
\hline Centre & $\begin{array}{l}\text { Examples of screening tests for } \\
\text { behaviour phenotypes }\end{array}$ & $\begin{array}{l}\text { Examples of present } \\
\text { behaviour-related } \\
\text { ENU-mutations }\end{array}$ & Website \\
\hline $\begin{array}{l}\text { Mammalian } \\
\text { Genetics Unit, } \\
\text { Harwell, UK }\end{array}$ & $\begin{array}{l}\text { Shirpa; learning and memory; wheel } \\
\text { running activity; open field behaviour }\end{array}$ & $\begin{array}{l}\text { Robotic, Rob: robotic motion; } \\
\text { Spin cycle, Scy: heading } \\
\text { bobbing, fits; Play68: long } \\
\text { circadian period }\end{array}$ & http://www.mut.har.mrc.ac.uk/ \\
\hline CMHD, Toronto & $\begin{array}{l}\text { Morris water maze; contextual \& cued } \\
\text { fear conditioning; pre-pulse inhibition }\end{array}$ & $\begin{array}{l}\text { 163-11-1: moves slowly, } \\
\text { wobbles, quiet; S338-12-23: } \\
\text { very small, shivering, } \\
\text { memory outlier }\end{array}$ & http://www.cmhd.ca/ \\
\hline $\begin{array}{l}\text { The Jakson } \\
\text { Laboratory, Bar } \\
\text { Harbor, ME }\end{array}$ & $\begin{array}{l}\text { Clams (comprehensive lab animal } \\
\text { monitoring system); acoustic startle } \\
\text { response }\end{array}$ & $\begin{array}{l}\text { NMF31: high threshold to } \\
\text { seizures }\end{array}$ & http://nmf.jax.org/ \\
\hline TMGC, Tennessee & $\begin{array}{l}\text { Open field activity; startle and pre- } \\
\text { pulse inhibition; hotplate test; tails } \\
\text { suspension test }\end{array}$ & $\begin{array}{l}\text { 22TNP: stress/behavioural } \\
\text { despair; 22TNJ-2: hyper- } \\
\text { activity in open field test; }\end{array}$ & $\begin{array}{l}\text { http://www.tnmouse.org/ } \\
\text { neuromutagenesis/ }\end{array}$ \\
\hline $\begin{array}{l}\text { Northwestern } \\
\text { University, } \\
\text { Chicago }\end{array}$ & $\begin{array}{l}\text { Body weight; hearing; elevated plus } \\
\text { maze and open field behaviour; } \\
\text { neuroendocrine response to stress; } \\
\text { circadian ryhthmicity; vision }\end{array}$ & $\begin{array}{l}\text { Overtime: lengthened free- } \\
\text { running period; Timecourse, } \\
\text { timeshare, half time: } \\
\text { shortened circadian period }\end{array}$ & http://genome.northwestern.edu/neuro/ \\
\hline $\begin{array}{l}\text { Norvatis Research, } \\
\text { San Diego }\end{array}$ & $\begin{array}{l}\text { Locomotor activity; learning and } \\
\text { memory; circadian rhythms; anxiety }\end{array}$ & Not available & http://web.gnf.org/index.shtml \\
\hline ORNL, Oak Ridge & $\begin{array}{l}\text { Primary behaviour: observation; } \\
\text { reaching; righting reflex; startle } \\
\text { response; prepulse inhibition; } \\
\text { habituation; locomotor activity; } \\
\text { learning and memory }\end{array}$ & $\begin{array}{l}\text { Baln2: shaking and head } \\
\text { tilting behaviour; } 6 \mathrm{TNK} \text { : } \\
\text { small, runted, juvenile } \\
\text { lethality, cerebral histological } \\
\text { abnormalities }\end{array}$ & http://lsd.ornl.gov/mgd/ \\
\hline $\begin{array}{l}\text { Riken institute, } \\
\text { Japan }\end{array}$ & $\begin{array}{l}\text { Shirpa; home-cage activity; open field } \\
\text { test; passive avoidance }\end{array}$ & $\begin{array}{l}\text { M100934: total activity high; } \\
\text { M100023: head tossing }\end{array}$ & $\begin{array}{l}\text { http://www.gsc.riken.go.jp/Mouse/ } \\
\text { main.htm }\end{array}$ \\
\hline Taiwan & $\begin{array}{l}\text { Locomotor activity; pentobarbital } \\
\text { responsiveness }\end{array}$ & Not available & http://mmp.sinica.edu.tw/ \\
\hline $\begin{array}{l}\text { University of } \\
\text { Pennsylvania }\end{array}$ & Circadian ryhthmicity & Rab3a (earlybird) & http://www.neurogenome.org/lab/ \\
\hline
\end{tabular}


al domains. Pitfalls of the high-throughput approach include difficulties in maintaining consistency and in the ability to define quantitative outliers by statistical means. Some tests appear to introduce a high variability and may be influenced by human interference. ${ }^{13}$ Problems may also be related to the number of successive tests mice are subjected to in order to increase test information density. ${ }^{14,15}$ As a complement to the high-throughput approach, highly specialized low-throughput screens targeting specific biological systems are beginning to provide additional classes of mutant phenotype.

\section{Moderate or low throughput screening}

Low-throughput screens do not appear to be subject to the same inconsistencies as discussed above. Although the number of mutants coming from these screens is lower, it would appear that mutant phenotypes are easily detectable due to the more rigorous methodology. By far the most common of the low-throughput programmes are those for circadian rhythm phenotypes. Circadian behaviour regulates diverse biological processes such as sleep homeostasis, locomotor activity, temperature regulation, metabolism, water/food intake and blood hormone levels. Generally these rhythms cycle on a $\sim 24 \mathrm{~h}$ basis and disturbances in rhythms have been associated with any number of human behavioural and psychiatric disorders. By screening for abnormal rhythms in progeny of mutagenised animals, one hopes therefore to identify mutations in genes that may also be associated with human disorders. The identification of the Clock gene in a mouse mutagenesis programme was the catalyst for the elucidation of the molecular basis of mammalian circadian function ${ }^{16-18}$ and, since its identification, many other genes acting within the circadian hierarchy have been identified and characterised. The earlybird (Ebd) mutation was identified in a modest screen of 500 animals. ${ }^{19}$ Sequencing identified a mutation in the synaptic vesicle trafficking protein, Rab3a. The mutant also displayed sleep pattern disturbances. Current screens are also producing a high number of abnormal phenotypes using the low-throughput wheel running activity screens. At Northwestern University, inheritance in at least 8 circadian activity mutants has been confirmed and mutation detection is underway. At Harwell also, circadian screens continue to identify abnormal phenotypes. Mouse lines confirmed include mutants with an abnormal circadian period, mutants with abnormal light-responsiveness, mutants with a reduced amplitude of wheel-running activity and mutants displaying multiple abnormal circadian parameters. ${ }^{20}$ One of the most striking mutants (PLAY68) is one where homozygotes display an average free running period of $\sim 27 \mathrm{~h}$ (Figure 2).

The utility, reliability and reproducibility of this lowthroughput screen, when compared to the faster high- throughput ones, is apparent as little human interference is needed in the screening process. This would suggest that other examples of low throughput screening where mini- a

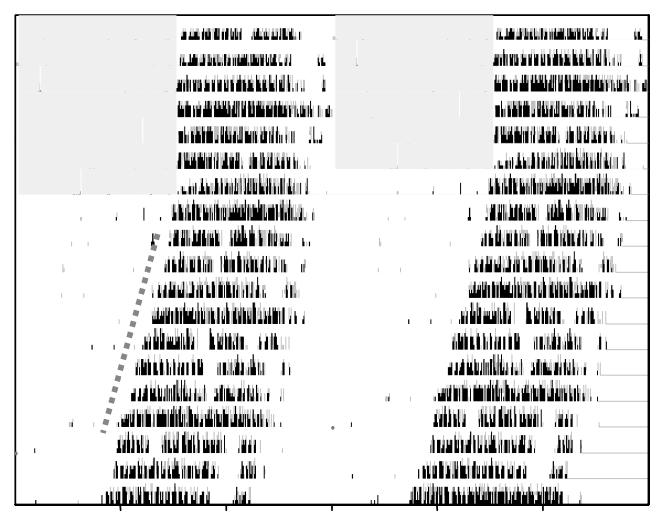

b
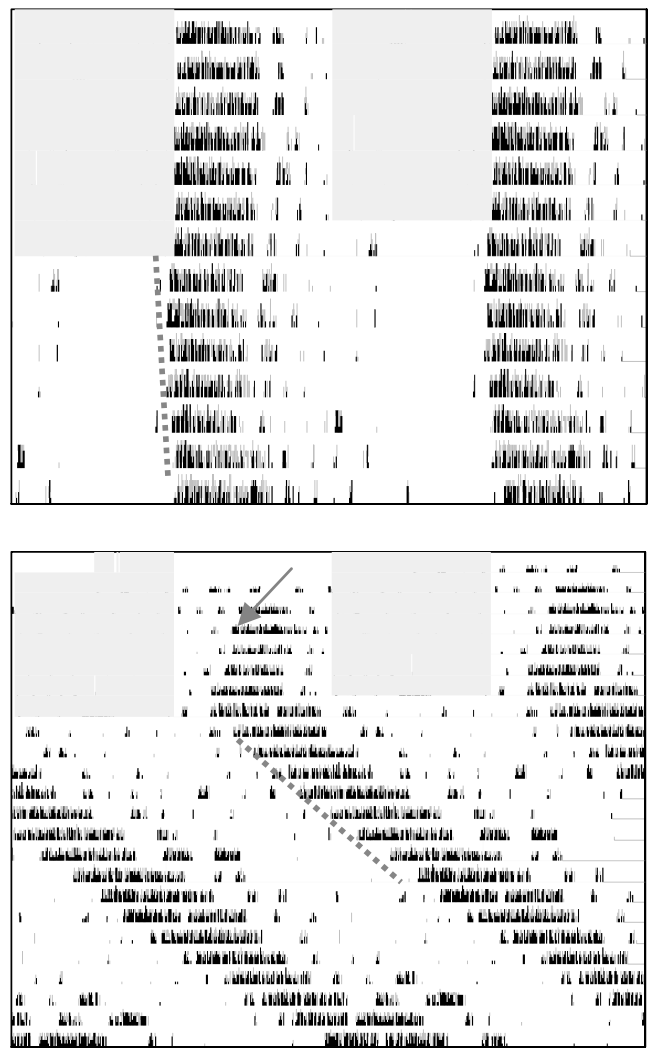

Figure 2 Abnormal circadian phenotype in the PLAY68 mutant. Representative images illustrating wheel running activity rhythm records for the ENU mutant line (PLAY68). Each image is a doubleplotted actogram of wheel running activity under light/dark conditions (LD) for 7 days, followed by constant dark conditions (DD) for approximately 14 days. Shaded blocks represent times at which the lights are on and short vertical bars represent periods of wheel-running activity. Records of littermate activity patterns for (a) wild-type, (b) heterozygous and (c) homozygous animals. In LD conditions the onset of activity usually coincides with the time at which lights are switched off $(\mathbf{a}, \mathbf{b})$. Note the delayed onset of activity of homozygous mutants represented by the arrow (c). The free-running period length is $23.68 \mathrm{~h}$ in wild-type, $24.23 \mathrm{~h}$ in heterozygotes and $26.73 \mathrm{~h}$ in homozygotes. 
mal human interference is used should be effective in identifying new classes of behavioural mutants. Recently a new method was designed to quantify levels of sociability and preference for social novelty in mice. ${ }^{21}$ This study describes in detail a novel sociability test apparatus that measures the tendency of test mice to approach and remain proximal to an unfamiliar mouse. This novel test may have potential applications for the interpretation of sociability or social avoidance in mouse models of autism, anxiety, depression and others.

\section{Use of modifier screens to target specific behavioural domains}

In addition to the need for improvement of behaviour screens, there have been modified reported methods aimed at targeting specific pathways thought to be involved in complex disorders such as schizophrenia, Parkinson's disease and drug addiction. The studies use chemical mutagenesis to screen for modifiers of existing mutant phenotypes. This approach has been used for many years in yeast, flies and worms (for a review on this and other mutagenesis screening strategies in Drosophila, see ${ }^{22}$ ), the hypothesis being that components of the same molecular pathway or biological process can be identified. Although more difficult and time-consuming to conduct in the mouse, the utility of this approach has recently been confirmed in a mutagenesis screen. Carpinelli and colleagues $^{23}$ screened ENU-mutagenised mice for suppression of the thrombocytopenia observed in $\mathrm{Mpl}{ }^{-/}$mice. From a total of 1575 mice screened, they cloned two independent loss-of-function alleles at the $c-M y b$ locus that ameliorated the $\mathrm{Mpl}^{-/-}$phenotype. Similar screens are currently being conducted worldwide including those for modifiers of neurodegenerative mutant phenotypes (Personal Communications). The results of a recent study have implications for the use of this approach in the dissection of psychiatric disorders. Speca et al. ${ }^{24}$ used a specific background strain targeted for a mutation in the dopamine transporter gene (DAT) as the dopaminergic (DA) system is thought to play a central role in the pathophysiology of schizophrenia. DAT -/- mice exhibit a spontaneous locomotor hyperactivity and they used this mutant line crossed with ENUmutagenised mice to identify compound mutant phenotypes where the locomotor abnormalities were exacerbated. The group was successful in identifying a number of novel lines with quantitatively altered levels of locomotor activity although some of these phenotypes were independent of the sensitised background. Although undoubtedly successful, the study has highlighted the difficulties associated with searching for novel loci associated with behavioural disorders. Even a relatively simple behaviour such as locomotor activity can be represented by a complex system of genetic interactions. Success in searching for ENU-modifiers in this way will be dependent on careful planning and understanding of mutant phenotypes, genetic crosses, behavioural testing and mapping strategies.

\section{Use of pharmacological agents to target psychiatric or behavioural domains}

In a similar manner, specific systems in the brain can be targeted using mutagenesis in combination with pharmacological agents. Screening for mutants that show an increased, decreased or abnormal drug responsiveness has the potential to uncover novel genetic components of these systems. Targeting systems in this way may also provide leads to understanding the genetic variability seen in human disorders such as schizophrenia and addiction. This approach was adapted ${ }^{25}$ to screen for mutagenised mice with altered serotonin responsiveness, the serotonergic system being implicated in a number of psychiatric disorders. In a pilot study they considered one 5HT receptor subtype (5HT2A) and one behavioural response to $5 \mathrm{HT} 2 \mathrm{~A}$ receptor activation (head twitch response). After careful consideration of background strain and assay conditions they conducted a pilot screen of 247 G1 animals. From this screen they identified both hyper- and hypo-responsive phenodeviants (approximately 1-2\% of the $\mathrm{G} 1$ population assayed), one of which was confirmed as a heritable hyper-responsive mouse line. Centres for highthroughput mutagenesis in the US have also used screens with pharmacological agents. ${ }^{26}$ Domains adapted by these groups are screens for locomotor responsiveness to cocaine administration and for anxiolytic responsiveness to ethanol administration. Screening for cocaine sensitivity has also been used in zebrafish ENU studies. ${ }^{27}$ Finally, several groups are targeting the GABAergic system using pharmacological screens. The Jackson Laboratory in the US and the Riken Genomic Sciences Centre in Japan are screening for mice with altered seizure susceptibility following exposure to pentylenetetrazol while the Mutagenesis Programme in Taiwan is screening for reduced responsiveness to pentobarbital (see respective websites in Table 2).

\section{Pleiotropic mutations. Further investigation into mutant phenotype}

Through the study of spontaneous and chemically-induced mouse mutants it is evident that single-gene mutations can affect multiple systems. These observations would argue for systematic investigation of mutant phenotypes that arise in mutagenesis screens. Listed below are a number of cases where, following the selection of mutants on the basis of an initial overt or behavioural phenotype, associated behavioural disturbances have been identified.

Approximately $2-3 \%$ of the population are affected by syndromic disorders with associated mental retardation. These disorders are associated with a broad spectrum of 
behavioural and neurological deficits including those affecting cognition, social behaviour, attention and sensorimotor function. Invariably, disorders such as velocardiofacial syndrome, Smith-Magenis syndrome and Cohen syndrome exhibit clear craniofacial anomalies suggesting a common etiology between craniofacial and behavioural/ psychiatric disturbances. Craniofacial phenotypes have been identified at a high rate in mutagenesis screens worldwide. At Harwell, approximately $10 \%$ of tested inherited mutants have a craniofacial phenotype. ${ }^{8}$ Selected mutants at Harwell are currently being systematically characterised at a behavioural level. One mutant line, batface, displays a complex of behavioural anomalies including cognitive and sensorimotor anomalies and an increased social dominance. Another phenotype frequently detected in dominant screens is hyperactivity/ circling. This behaviour in mice can be precipitated by pharmacological alteration of the dopaminergic system and mutants with this phenotype have sparked an interest through their applicability to the study of hyperactivity disorders. The spontaneous mutant, coloboma, was first identified as it exhibited head bobbing, hyperactivity and ocular dysmorphology, ${ }^{28}$ with hippocampal plasticity ${ }^{29}$ and neurodevelopmental abnormalities. ${ }^{30}$ The coloboma deletion includes the synaptosomal protein SNAP25 and reduced levels of this pre-synaptic protein result in dopaminergic anomalies in the dorsal striatum. ${ }^{31}$ Circling phenotypes detected in mutagenesis screens map to a number of chromosomal loci, including many at a highly mutable locus on mouse chromosome $4 .^{32}$ Mutants at the chromosome 4 locus can also present with a long circadian period. ${ }^{33}$ A third class of visible phenotype with associated behavioural anomalies is tail dysmorphology. For example, mutations in the Zic family of transcription factors can result not only in tail dysmorphologies but also in specific neurological and behavioural deficits. Mutations in Zic1 result in motor deficits and ataxia whereas mutations in Zic2 lead to acoustic startle and PPI deficits. ${ }^{34}$ Furthermore, Zic2 may exert its effects through the dopaminergic system, more specifically through a repression of dopamine D1A receptor transcription. ${ }^{35}$ Mutant lines with dominant tail dysmorphologies continue to be identified in mutagenesis screens at a high rate, ${ }^{36}$ many of these mapping to novel or previously uncharacterized loci.

Systematic behavioural analysis of mouse lines generated in mutagenesis screens, and indeed of all targeted mutants, promises to uncover novel gene functions that are relevant to research into human behavioural and psychiatric disorders. For example, recent evidence would suggest that several genes critical for the generation and maintenance of biological rhythms serve neurobiological (and other) functions in addition to their primary circadian role. Behavioural studies, initially in Drosophila mutants ${ }^{37}$ and subsequently in mouse Per mutants, ${ }^{38}$ implicated the Per family of genes in mechanisms of drug sensitisation and reward. Moreover, the Per2 gene has been shown to be engaged in the regulation of the glutamatergic system and allelic variants are associated with altered consumption of alcohol in mice and humans. ${ }^{39}$ These novel associations are not restricted to the Per genes. Mice lacking a functional Clock gene show disturbances in the dopaminergic system with abnormal cocaine sensitisation and reward responses. ${ }^{40}$ These mice had previously shown an increase in exploratory activity and escape-seeking behaviour in a comprehensive study of emotionality. ${ }^{41}$ Additionally, Clock homozygotes reveal disturbances in feeding with hyperphagy, obesity and metabolic abnormalities including hyperglycemia and hypoinsulinemia. ${ }^{42}$ Upon considering the spectra of behavioural anomalies in circadian mutants, one group has been prompted to scan a subset of these genes for association with psychiatric disorders including bipolar I disorder, schizoaffective disorder and schizophrenia. ${ }^{43}$ Although only modest associations have been identified in this study, the authors encourage a more thorough investigation. Further studies implicate a breakdown in circadian homeostasis as a factor in sleep/wake disturbances in neurodegeneratvie disorders. Morton et $a l^{44}$ carried out extensive studies on a mouse transgenic model of Huntington's Disease. These mice exhibit a progressive loss of circadian function with an associated loss of pacemaker gene oscillation within the suprachiasmatic nucleus of the hypothalamus.

\section{Behavioural phenotypes in mutants with a homo- zygous embryonic phenotype}

In the previous section, we have identified several examples where certain signature phenotypes are associated with additional behavioural anomalies. In these cases, visible (and behavioural) phenotypes in heterozygotes may be related to the neurodevelopmental phenotypes seen in homozygotes. By extrapolation, any mutant displaying a homozygous neurodevelopmental phenotype could express a behavioural phenotype in the adult heterozygous state. Currently, mutagenesis programs frequently focus either on phenotypes observable in adulthood or on embryonic phenotypes while reciprocal analysis of mutants identified in either domain is never systematically carried out. However, it should be considered that anomalies in development might be related to atypical neurobehavioral alterations in adults. Such associations have been considered as a basis for susceptibility to psychiatric disorders, for example mutant mice with hippocampal development anomalies can express features of schizophrenia. ${ }^{45}$ One such specific relationship has been characterised for mice with a targeted null mutation in the Notch1 gene. Notch1 homozygotes die in the second half of gestation with a visible somite segmentation anomaly in the first half of gestation ${ }^{46}$ whereas early homozygous embryos are deficient in neural stem cells. ${ }^{47}$ Mice hetero- 
zygous for this Notch1 mutation, although they do not express an overt phenotype, do show specific deficits in spatial learning. ${ }^{48}$ We investigated this further in homozygous-lethal mutants that were being characterised in a region-specific mutagenesis screen at Harwell. ${ }^{49}$ The region under study on mouse chromosome 13 shares a block of synteny with part of human chromosome $6 \mathrm{p}$, associated with syndromic disorders that often include behavioural deficits. Ten mutant lines with a spectrum of homozygous embryonic phenotypes were characterised using a standardised battery of high-throughput behavioural tests (for details see www.eumorphia.org). Five of the ten lines tested exhibited specific and significant behavioural anomalies in heterozygotes, three of which had overt neurodevelopmental anomalies in the homozygous state. Although this analysis was cursory and small-scale, the findings would suggest that the systematic phenotyping of heterozygous carriers of (neuro)developmental mutations may provide a new paradigm for the recovery of strains relevant to the study of adult-onset behavioural and neurological disorders.

\section{Outlook}

The potential to phenotype mice in behavioural domains has progressed dramatically over the past decade. In fact a large proportion of targeted mutants and chemicallymutagenised mice show at least some form of neurological or behavioural anomaly. However, it is our belief that improvements in phenotyping and in our analysis of phenotypic data should continue to provide an increase in our understanding of neurological and behavioural dysfunction in humans. Screening efforts worldwide continue to identify mutants in systematic and specific behavioural domains. The continued use of this approach, in parallel with gene-targeting, promises to provide ample tools with which to study gene function in disease models.

\section{References}

1 Inoue K, Lupski JR: Genetics and genomics of behavioral and psychiatric disorders. Curr Opin Genet Dev 2003; 13: 303-309.

2 Gottesman II, Gould TD: The endophenotype concept in psychiatry: etymology and strategic intentions. Am J Psychiatry 2003; 160: 636-645.

3 Bolivar V, Cook M, Flaherty L: List of transgenic and knockout mice: behavioral profiles. Mamm Genome 2000; 11: 260-274.

4 Hitotsumachi S, Carpenter DA Russell WL: Dose-repetition increases the mutagenic effectiveness of N-ethyl-N-nitrosourea in mouse spermatogonia. Proc Natl Acad Sci USA 1985; 82: $6619-6621$.

5 Quwailid MM, Hugill A, Dear N et al: A gene-driven ENU-based approach to generating an allelic series in any gene. Mamm Genome 2004; 15: 585-591.

6 Patton EE Zon LI: The art and design of genetic screens: zebrafish. Nat Rev Genet 2001; 2: 956-966.

7 Nolan PM, Kapfhamer D Bucan M: Random mutagenesis screen for dominant behavioral mutations in mice. Methods 1997; 13: 379-395.
8 Nolan PM, Peters J, Strivens M et al: A systematic, genome-wide, phenotype-driven mutagenesis programme for gene function studies in the mouse. Nat Genet 2000; 25: 440-443.

9 Rogers DC, Fisher EM, Brown SD, Peters J, Hunter AJ Martin JE: Behavioral and functional analysis of mouse phenotype: SHIRPA, a proposed protocol for comprehensive phenotype assessment. Mamm Genome 1997; 8: 711-713.

10 Keays DA, Nolan PM: N-ethyl-N-nitrosourea mouse mutants in the dissection of behavioural and psychiatric disorders. Eur J Pharmacol 2003; 480: 205-217.

11 Isaacs AM, Oliver PL, Jones EL et al: A mutation in Af4 is predicted to cause cerebellar ataxia and cataracts in the robotic mouse. J Neurosci 2003; 23: 1631-1637.

12 Isnard $\mathrm{P}$, Core $\mathrm{N}$, Naquet $\mathrm{P}$ Djabali M: Altered lymphoid development in mice deficient for the MAF4 proto-oncogene. Blood 2000; 96: 705-710.

13 Kas MJ Van Ree JM: Dissecting complex behaviours in the postgenomic era. Trends Neurosci 2004; 27: 366-369.

14 Tecott LH, Nestler EJ: Neurobehavioral assessment in the information age. Nat Neurosci 2004; 7: 462-466.

15 Crabbe JC Morris RG: Festina lente: late-night thoughts on highthroughput screening of mouse behavior. Nat Neurosci 2004; 7: $1175-1179$.

16 Vitaterna $\mathrm{MH}$, King DP, Chang AM et al: Mutagenesis and mapping of a mouse gene, Clock, essential for circadian behavior. Science 1994; 264: 719-725.

17 King DP, Zhao Y, Sangoram AM et al: Positional cloning of the mouse circadian clock gene. Cell 1997; 89: 641-653.

18 Antoch MP, Song EJ, Chang AM et al: Functional identification of the mouse circadian Clock gene by transgenic BAC rescue. Cell 1997; 89: 655-667.

19 Kapfhamer D, Valladares O, Sun Y et al: Mutations in Rab3a alter circadian period and homeostatic response to sleep loss in the mouse. Nat Genet 2002; 32: 290-295.

20 Bacon Y, Ooi A, Kerr S et al: Screening for novel ENU-induced rhythm, entrainment and activity mutants. Genes Brain Behav 2004; 3: 196-205.

21 Moy SS, Nadler JJ, Perez A et al: Sociability and preference for social novelty in five inbred strains: an approach to assess autisticlike behavior in mice. Genes Brain Behav 2004; 3: 287-302.

22 St Johnston D: The art and design of genetic screens: Drosophila melanogaster. Nat Rev Genet 2002; 3: 176-188.

23 Carpinelli MR, Hilton DJ, Metcalf D et al: Suppressor screen in Mpl-/- mice: c-Myb mutation causes supraphysiological production of platelets in the absence of thrombopoietin signaling. Proc Natl Acad Sci USA 2004; 101: 6553-6558.

24 Speca DJ, Rabbee N, Chihara D, Speed TP Peterson AS: A genetic screen for behavioral mutations that perturb dopaminergic homeostasis in mice. Genes Brain Behav 2005; 0: doi: 10.1111/ j.1601-183X.2005.00127.x.

25 Weiss KC, Kim DY, Pawson CT Cordes SP: A genetic screen for mouse mutations with defects in serotonin responsiveness. Brain Res Mol Brain Res 2003; 115: 162-172.

26 Goldowitz D, Frankel WN, Takahashi JS et al: Large-scale mutagenesis of the mouse to understand the genetic bases of nervous system structure and function. Brain Res Mol Brain Res 2004; 132: 105-115.

27 Darland T Dowling JE: Behavioral screening for cocaine sensitivity in mutagenized zebrafish. Proc Natl Acad Sci USA 2001; 98: 11691-11696.

28 Hess EJ, Jinnah HA, Kozak CA Wilson MC: Spontaneous locomotor hyperactivity in a mouse mutant with a deletion including the Snap gene on chromosome 2. J Neurosci 1992; 12: $2865-2874$.

29 Steffensen SC, Wilson MC, Henriksen SJ: Coloboma contiguous gene deletion encompassing Snap alters hippocampal plasticity. Synapse 1996; 22: 281-289.

30 Heyser CJ, Wilson MC, Gold LH: Coloboma hyperactive mutant exhibits delayed neurobehavioral developmental milestones. Brain Res Dev Brain Res 1995; 89: 264-269. 
31 Raber J, Mehta PP, Kreifeldt $\mathrm{M}$ et al: Coloboma hyperactive mutant mice exhibit regional and transmitter-specific deficits in neurotransmission. J Neurochem 1997; 68: 176-186.

32 Kiernan AE, Erven A, Voegeling S et al: ENU mutagenesis reveals a highly mutable locus on mouse chromosome 4 that affects ear morphogenesis. Mamm Genome 2002; 13: 142-148.

33 Pickard GE, Sollars PJ, Rinchik EM, Nolan PM, Bucan M: Mutagenesis and behavioral screening for altered circadian activity identifies the mouse mutant, Wheels. Brain Res 1995; 705: $255-266$.

34 Ogura H, Aruga J, Mikoshiba K: Behavioral abnormalities of Zic1 and Zic2 mutant mice: implications as models for human neurological disorders. Behav Genet 2001; 31: 317-324.

35 Yang Y, Hwang CK, Junn E, Lee G Mouradian MM: ZIC2 and Sp3 repress Sp1-induced activation of the human D1A dopamine receptor gene. J Biol Chem 2000; 275: 38863-38869.

36 Bogani D, Warr N, Elms P et al: New semidominant mutations that affect mouse development. Genesis 2004; 40: 109-117.

37 Andretic R, Chaney S Hirsh J: Requirement of circadian genes for cocaine sensitization in Drosophila. Science 1999; 285: $1066-1068$.

38 Abarca C, Albrecht U Spanagel R: Cocaine sensitization and reward are under the influence of circadian genes and rhythm. Proc Natl Acad Sci USA 2002; 99: 9026-9030.

39 Spanagel R, Pendyala G, Abarca C et al: The clock gene Per2 influences the glutamatergic system and modulates alcohol consumption. Nat Med 2005; 11: 35-42.

40 McClung CA, Sidiropoulou K, Vitaterna $\mathrm{M}$ et al: Regulation of dopaminergic transmission and cocaine reward by the Clock gene. Proc Natl Acad Sci USA 2005; 102: 9377-9381.

41 Easton A, Arbuzova J, Turek FW: The circadian Clock mutation increases exploratory activity and escape-seeking behavior. Genes Brain Behav 2003; 2: 11-19.

42 Turek FW, Joshu C, Kohsaka A et al: Obesity and metabolic syndrome in circadian Clock mutant mice. Science 2005; 308: $1043-1045$.

43 Mansour HA, Wood J, Logue T et al: Association study of eight circadian genes with bipolar I disorder, schizoaffective disorder and schizophrenia. Genes Brain Behav 2005; 0: doi: 10.1111/ j.1601-183X.2005.00147.x.

44 Morton AJ, Wood NI, Hastings MH, Hurelbrink C, Barker RA, Maywood ES: Disintegration of the sleep-wake cycle and circadian timing in Huntington's disease. J Neurosci 2005; 25: $157-163$.

45 Scheibel AB, Conrad AS: Hippocampal dysgenesis in mutant mouse and schizophrenic man: is there a relationship? Schizophr Bull 1993; 19: 21-33.

46 Conlon RA, Reaume AG Rossant J: Notch1 is required for the coordinate segmentation of somites. Development 1995; 121: $1533-1545$.

47 Hitoshi S, Alexson T, Tropepe V et al: Notch pathway molecules are essential for the maintenance, but not the generation, of mammalian neural stem cells. Genes Dev 2002; 16: 846-858.

48 Costa RM, Honjo T, Silva AJ: Learning and memory deficits in Notch mutant mice. Curr Biol 2003; 13: 1348-1354.

49 Bogani D, Willoughby C, Davies J et al: Dissecting the genetic complexity of human $6 \mathrm{p}$ deletion syndromes using a regionspecific, phenotype-driven mouse screen. Proc Natl Acad Sci U S A 2005; 102: 12477-12482.

50 Irwin S: Comprehensive observational assessment: Ia. A systematic, quantitative procedure for assessing the behavioral and physiologic state of the mouse. Psychopharmacologia 1968; 13: 222-257.

51 Wassif CA, Zhu P, Kratz L et al: Biochemical, phenotypic and neurophysiological characterization of a genetic mouse model of RSH/Smith - Lemli - Opitz syndrome. Hum Mol Genet 2001; 10: $555-564$
52 Crabbe JC, Cotnam CJ, Cameron AJ et al: Strain differences in three measures of ethanol intoxication in mice: the screen, dowel and grip strength tests. Genes Brain Behav 2003; 2: 201-213.

53 Isaacs AM, Davies KE, Hunter AJ et al: Identification of two new Pmp22 mouse mutants using large-scale mutagenesis and a novel rapid mapping strategy. Hum Mol Genet 2000; 9: 1865-1871.

54 Hall ED, Wolf DL, Althaus JS, Von Voigtlander PF: Beneficial effects of the kappa opioid receptor agonist U-50488 $\mathrm{H}$ in experimental acute brain and spinal cord injury. Brain Res 1987; 435: $174-180$.

55 Peled-Kamar M, Lotem J, Wirguin I, Weiner L, Hermalin A, Groner Y: Oxidative stress mediates impairment of muscle function in transgenic mice with elevated level of wild-type Cu/Zn superoxide dismutase. Proc Natl Acad Sci U S A 1997; 94: $3883-3887$

56 Dalvi A, Lucki I: Murine models of depression. Psychopharmacology (Berl) 1999; 147: 14-16.

57 Gerlai R, Millen KJ, Herrup K, Fabien K, Joyner AL, Roder J: Impaired motor learning performance in cerebellar En-2 mutant mice. Behav Neurosci 1996; 110: 126-133.

58 Bourin M, Hascoet M: The mouse light/dark box test. Eur Pharmacol 2003; 463: 55-65.

59 Crawley JN: Neuropharmacologic specificity of a simple animal model for the behavioral actions of benzodiazepines. Pharmacol Biochem Behav 1981; 15: 695-699.

60 Holmes A, Hollon TR, Gleason TC et al: Behavioral characterization of dopamine D5 receptor null mutant mice. Behav Neurosci 2001; 115: 1129-1144.

61 Ohl F, Roedel A, Binder E, Holsboer F: Impact of high and low anxiety on cognitive performance in a modified hole board test in C57BL/6 and DBA/2 mice. Eur J Neurosci 2003; 17: 128-136.

62 Monnier C, Lalonde R: Elevated (+)-maze and hole-board exploration in lurcher mutant mice. Brain Res 1995; 702: 169-172.

63 Lister RG: The use of a plus-maze to measure anxiety in the mouse. Psychopharmacology (Berl) 1987; 92: 180-185.

64 Tang X, Orchard SM, Sanford LD: Home cage activity and behavioral performance in inbred and hybrid mice. Behav Brain Res 2002; 136: $555-569$.

65 Moretti P, Bouwknecht JA, Teague R, Paylor R, Zoghbi HY: Abnormalities of social interactions and home-cage behavior in a mouse model of Rett syndrome. Hum Mol Genet 2005; 14: $205-220$.

66 Porsolt RD, Le Pichon M, Jalfre M: Depression: a new animal model sensitive to antidepressant treatments. Nature 1977; 266: $730-732$.

67 Jones BJ, Roberts DJ: The quantiative measurement of motor inco-ordination in naive mice using an acelerating rotarod. J Pharm Pharmacol 1968; 20: 302-304.

68 Torres G, Meeder BA, Hallas BH, Gross KW, Horowitz JM: Preliminary evidence for reduced social interactions in Chakragati mutants modeling certain symptoms of schizophrenia. Brain Res 2005; 1046: 180-186.

69 Messeri P, Eleftheriou BE, Oliverio A: Dominance behavior: a phylogenetic analysis in the mouse. Physiol Behav 1975; 14: $53-58$.

70 Long JM, LaPorte P, Paylor R, Wynshaw-Boris A: Expanded characterization of the social interaction abnormalities in mice lacking Dvl1. Genes Brain Behav 2004; 3: 51-62.

71 Willott JF, Carlson S: Modification of the acoustic startle response in hearing-impaired C57BL/6J mice: prepulse augmentation and prolongation of prepulse inhibition. Behav Neurosci 1995; 109: 396-403.

72 Richardson GS, Moore-Ede MC, Czeisler CA, Dement WC: Circadian rhythms of sleep and wakefulness in mice: analysis using long-term automated recording of sleep. Am J Physiol 1985; 248: R320-R330 